\title{
The Purpose of Kata: When, Why, and for Whom Kata Forms Have Occurred in Okinawa
}

Authors' contribution:

A) conception and design of the study

B) acquisition of data

C) analysis and interpretation of data

D) manuscript preparation

E) obtaining funding

\section{Edvard Sefer}

Independent Consultant, Founder (Soke) of the MonkuJutsu Art Style of Self Defense

ABSTRACT

The primary aim of this research is to prove that the Kata forms were created for the self-defense of a weaker person against a stronger one. The materials and methods used for this research include a study of literature, old Chinese drawings, practical experience with Monku Jutsu, acupressure point fighting, history, Kata forms, anatomy, and body kinetics, as well as Chinese and modern philosophy.

The most significant result of this study is a new approach to understanding Kata forms, with the most important conclusion being that Kata forms are an art of selfdefense that do not require fingers like iron or a body as hard as a rock in order for this knowledge to be used in a real life situation.

KEYWORDS Kata forms, women's self-defense, Kata history and philosophy

\section{Article}

To begin, for those who are not familiar with karate, I have to explain that Kata forms were created for the autonomous training of self-defense - that is, without a partner. Another important note is that Patrick McCarthy, who is accepted by many as the foremost Western historian of karate-do literature, says that credible pre-twentieth century documents explaining the history and evolution of karate are virtually non-existent (McCarthy 2016, p. 22). Everything we know today was saved for us by means of the oral tradition of the Okinawan-Japanese karate masters. The only pre-twentieth century book describing elements of value is $\mathrm{Wu}$ Bei Zhi. This will be explained later on. Even in the case of the names of historical persons, Kata forms, or self-defense actions, we do not have any old written documents. For this reason, I will use today's most commonly used names. I will look for answers in a logical way, not through dogmas introduced by specific groups. A dogma is a belief so strong that the ones adhering to it become unwilling to discuss it rationally.

\section{The Kata Purpose}

We must start with Gichin Funakoshi, who is widely recognized by many as the father of modern karate. He clearly wrote: "I have always stressed the point in my teaching that Karate is a defensive Art and must never serve offensive purposes" (Funakoshi 2012, p. 93). Besides that, it is important to know the second of his Guiding Principles of Karate (Funakoshi 2012, p. 23). This second principle was, due to its importance, 
even written as an epitaph on his tombstone: "There is no first attack in karate" (Karate ni sente nashi). In this way, Funakoshi clearly delineated that Kara Te (empty hand) and Kata were created for self-defense. Besides Funakoshi, it is important to follow the philosophy of the famous warlord and counsellor of the eastern Han Dynasty, Cao Cao (155-220AD), who wrote "If the enemy attacks, he becomes vulnerable."

In real life, a person does not attack if he is not convinced of his victory. The attacker is always bigger, stronger, or more skilled - or at least he thinks so. Nobody attacks if he knows that he will be beaten. In real life, ordinary people need to know the art that will help them to defend themselves from bigger, heavier, stronger, and skilled attackers. We need to combine Funakoshi's epitaph and the fact that only the stronger attack the weaker to come to the conclusion that Kata is meant to be a weaker person's self-defense art against a stronger person.

The second important thing to understand about Kata forms is that we must distinguish between the sport of karate and real life street situations.

During the scope of my research, which has lasted more than fifteen years, I have only focused on Kata forms. I did not have an interest in study in the sport of karate or any other martial art in any specific style because, today, the martial arts are sports. Two fighters in a sporting competition attack each other, and this is not the soul of Kata. Kata gives you the knowledge, if attacked, to defend yourself and kill an attacker in two seconds. On August 3, 2016, even the International Olympic Committee made the decision to rank karate as a sports discipline for the 2020 Olympic Games. In this way, karate has evolved over about 100 years from a martial art of self-defense to a sporting game. The history of modern sports goes back only a hundred years before martial arts. Just remember that the new era of the Olympic Games started in 1896, and the teaching of Kara-Te began in Japan after the First Annual Athletic Exhibition in 1922. In 1939 Funakoshi built the first Shotokan training hall in Tokyo. Besides that, all of today's martial arts are sports. Sports are games, and games have rules, limited place, Agon, and Ludus (Caillois, Fink, Huizinga 2003, pp. 10-191). Agon is the rule of competitor equality and Ludus includes the rules that make things unnecessarily more difficult and, at same time, prolong the sporting fight so that those who paid for entrance tickets can satisfy their need for violence. I find the most significant difference between sports and real life situations to be that in sporting games you can always give up and surrender to protect yourself from injury and your competitor will respect that; in real life, the winning attacker will not respect your wish.

\section{When As a Historical Aspect}

The masters created Kata long before the modern-era sport of karate began. There is not much evidence to support the idea that the Kata forms we know today existed before Fāng Qinniáng, the creator of the White Crane style. She lived in the prefecture of Quanzhou in the Fujian province during the reign of the Jiajing Emperor (1521-1566) of the Ming Dynasty. You may find many sources stating that she was born in the mideighteenth century, but this is incorrect as there is evidence that several White Crane style Kata were created earlier. The exception is perhaps San Chin Kata, which originated in Fujian and is sometimes connected to Bodidharma. Wanshu Kata is accredited to Chinese diplomat Wang (1621-1689), who was sent by the Qing government in 1683 to Okinawa. Kusanku Kata refers to Kwang Shang Fu. He was a martial artist sent from the Chinese Fujian province around 1756 as an ambassador of the Qing Dynasty to Ryukyu, where he died in 1762. Wanshu and Kusanku Kata clearly show when Fang lived. Sokon Matsamura, who lived during the nineteenth century, was one of the few masters and maybe the last who knew the secrets hidden within Kata. It is possible that he was the creator of Chinto Kata. In the case of Seisan Kata, we know only that it is derived from the White Crane style. We do not know when each Kata was created, but it is commonly accepted that these forms have roots in the White Crane style.

During my research, I confirmed that all known old Kata forms follow the same rules of the White Crane style. We can say for certain that all of the old and original Kata were created by the Chinese or Okinawans with Chinese roots. Kata forms were not created for ballet or dance, and even from the time of the martial arts ban until the beginning of the twentieth century they were performed and created to look as if someone was dancing in a rice field. There are no original written instructions on how to perform or use Kata. The reason 
for this can be found in the ban and death penalty for martial arts training. Over time, different people started to perform the same Kata in different ways because they forgot some of the moves - as in the "telephone" game where people forget to pass on a word or something is lost in translation - and possibly even because they had the wrong perception of what Kata was made for or just because they were bad observers. Today, we have as many Kata explanations as schools and masters. What is common to all of the explanations is that they all have the strong man approach. Face to face, they fight and be brave and honest without fear, which is typically a sporting approach. In my research, which was based on several sciences, I searched for the original explanation. I observed YouTube videos with Kata performed in different styles to come to my conclusions. Old $8 \mathrm{~mm}$ black and white films were particularly helpful. In these films, old masters perform Kata in a way that would cause sporting judges to immediately remove them from further competition. Kata knowledge in the past was very valuable because the knowledge hidden in Kata helped its followers to survive, so whoever invented Kata kept this knowledge to themselves and only passed it on to their successor or successors as a family secret or tradition. As they could not hide their training, masters taught other people Kata, but did not reveal any secrets to them. It would be senseless to spread this knowledge to everyone because if Kata were common knowledge, it would not offer any advantage in the case of being attacked. Thanks to the Japanese masters who collected and preserved Kata as in many countries, scientists have been able to collect national songs and stories so that, today, everybody can learn to perform Kata even without knowing what it is meant for. This led to the situation that we have today where even Kata performances are a sporting genre. Sporting performance includes the evaluation of an artistic impression by difficulty, and this led Kata to evolve into a nicer sport that involves a more complicated execution. The purpose has become unimportant.

To understand something, you must first know its history. Confucius (551-479BC) wrote, "Study the past, if you would divine the future," and Johan Wolfgang von Goethe (1749-1823) also said, "The history of a scienceis that science alone." Following the example of these two famous men, we will start with history.

Most sources first discuss Bodidharma when beginning with martial arts.

Bodidharma was a Buddhist monk who lived during the fifth or sixth century BC. He is credited with bringing the martial art of self-defense to the Shaolin temple. That martial art later evolved into Kung Fu and all of the other martial arts we know today. The Ryukyu archipelago, including its biggest island, Okinawa, is close to China and sea streams that helped boats reach the islands as early as during the Stone Age. Thanks to the people from China, the art of self-defense came to Okinawa after Bodidharma. This undoubtedly occurred in 1392 when thirty-six Chinese families were sent to Okinawa by the Hongwu Emperor of the Ming Dynasty. They came there at the request of the Ryukyuan king to manage oceanic dealings in the kingdom. These thirtysix families were from the Fujian province. The Fujian province is the home of a southern Shaolin temple. Many Ryukyuan officials were descended from these Chinese immigrants and were born in China or had Chinese grandfathers. They assisted the Ryukyuan in advancing their technology and diplomatic relations. In 1429, King Shoo Hashi unified the three Ryūkyū kingdoms into one and a period of great peace and relative prosperity began. At that time, many Chinese people moved to the Ryukyu Islands to serve the government or engage in business. During this period and also later on, the biggest island of the Ryukyu archipelago, Okinawa, was like the World Trade Center - it was a place where all nations took part in trade. After King Shoo Hashi, his son, Shoo Shin, came to power. In 1477, he banned the practice of martial arts. The ban on martial arts training officially lasted until 1902 when the Commissioner of Education, Shintaro Ogawa, recommended that it be included in the physical education program of Okinawa's first middle school. The ban on using weapons and/or the training of martial arts was introduced in same way as nowadays it is forbidden to carry weapons in most countries. This is reserved for police, soldiers, and people with special licenses. The leading class has always made rules to suppress the common people who work for them, making their own lives richer in the process. Bans on weapons and martial arts are the first step in the self-protection of the leading class. In this manner, the leading class protects their interests from the common people. By introducing the ban, King Shoo Shin established a base for the development of Kata. Before the ban, people could train normally in pairs, with one person attacking and one defending. However, with the emergence of the ban, training in pairs was no longer allowed for common people. Common people always find the way to disobey rules (Certeau 1990, pp. 40-42) so to continue training, the masters created Kata and performed Kata as a dance 
because dancing was not forbidden. To date, one of the rare preserved and most crucial pre-ban documents is the Bubishi combat manual. Originally named Wu Bei Zhi, it was edited by Mao Yuanyi (1594-1640) and is the most comprehensive military book in Chinese history. Due to its unique existence and value, you can find drawings out of the Wu Bei Zhi in the Bubishi written by Patrick McCarthy (several editions have been published since 1995), the Bubishi Martial Art Spirit by George Aleksander (2015), the original Fu Roku Bubishi: The Original Translation of One of Okinawan Karate's Most Important and Valuable Texts by an unknown author (2016), and the Bubishi by Roland Habsetzer (2009). There is also a lesser known version in Japanese by Tokashiki Iken: Okinawa Karate Hidden Bubishi (1995). All of the modern Bubishi books include the original text and forty-eight drawings. It is a pity that the drawings in these books are not the same. You may find several unimportant differences at first glance, but these make a huge difference if properly understood. The original text is symbolic; for example, "one thousand pounds fall to the ground" and "bell and drums sounding together" tell, like a riddle, only the well-educated person what the drawing depicts. In the Wu Bei Zhi, you can find drawings that show training in pairs. When comparing these drawings to Kata, I do on a daily basis, I discovered that the drawings depict, through an old Chinese hidden method, the movements you find in Kata. Wu H. wrote about how to understand old Chinese drawings (Bernhart, Xin, Chongzheng, Calhill, Shaojun, Wu 1997). In the past, these drawings were priceless, as a person who understood and was able to perform these techniques was capable of saving his life. If everybody knew these secrets, this would have removed their value. That is why, when observing the drawings, you must be aware of the fact that the people who made these drawings purposely focused your observation on unimportant details and, at same time, hid important ones - much like magicians. These drawings are meant to function as a reminder to followers. We are used to looking at drawings as photos that depict one single moment. In the interest of discretion, in the case of ancient Chinese drawings, the authors often drew practitioners in such a way: "If you are going to grab my throat, I will pull your hand down" (have a look at the Seiench in Bubishi drawing below). You must observe all of the details, even small ones such as who is smiling or which muscles are strained. The difference between these drawings and Kata is only that in Kata, you do not see the training partner. Here, I used the original drawings from the Fu Roku Bubishi because I find that, in McCarthy's Bubishi redrawing, several small but important details were lost that can lead to improper understanding. However, discussing the correctness of these drawings is not the purpose of this article.

Figure 1. Below action you may find in Kata Seienchi-Seuchin

Source: Alexander, Penland 2015, p. 114.
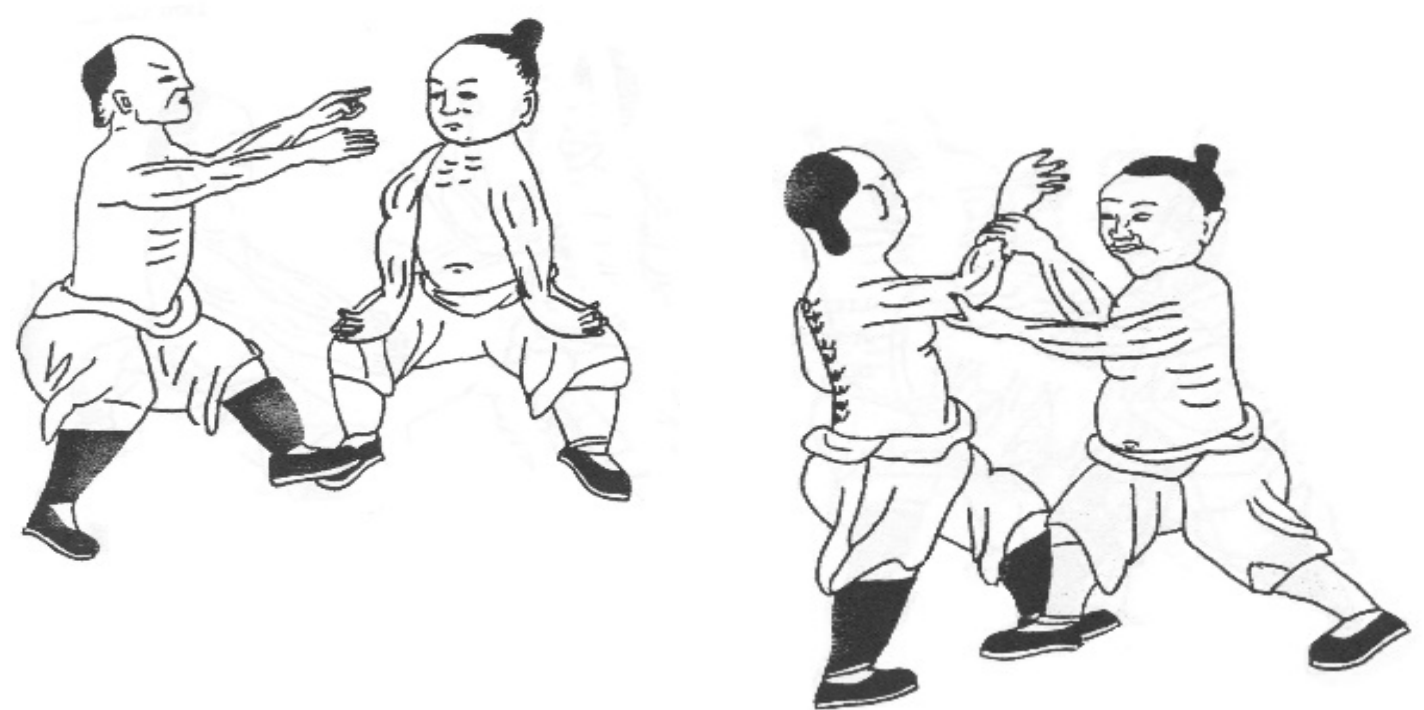

Figure 2. This action you may find in Kata San Chin, (Pinan), Sun Su and other

Source: Alexander, Penland 2015, p.127. 


\section{Why As a Social Aspect}

To the north of Ryukyu, an archipelago in Japan, the first permanent capital was founded in 710 at Nara. Nara became a center of Buddhist art, religion, and culture. In 1600, Tokugawa Lejasu came to power. He gave land to his supporters and set up his feudal government at Edo. This so-called Edo period lasted until 1868, when the Meji period began. The Edo period was a long era characterized by relative peace, stability, and prosperity under the tight control of the Tokugawa shogunate, which ruled from the eastern city of Edo, now called Tokyo. Japan was a closed country and did not have much contact with the outside world. This period is very well described by the James Clavell book, Shogun (Clavell 1975). During this time, harsh penalties such as crucifixion, beheading, and death by boiling were given for even minor offenses. One of the most significant social policies of the Tokugawa shogunate was the freezing of Japan's social classes. They had four occupation hierarchies: the samurai, peasant farmers, artisans, and merchants. The law did not permit a Japanese person to adopt a different occupation outside of the one he was born into or to marry a person of a different occupation. Outside of these four classes, there were also court nobles, clergymen, and the untouchable class. Such social relations were the same in family life. So even within a family, a person had a precise role.

The Japanese occupied Okinawa in 1609 and, at the same time, the status of Japanese women and even the female Japanese samurais known as the Onna-bugeisha diminished significantly. Onna-bugeisha literally means "female martial artist." The wives of samurais who were trained to protect their homes while the samurais were away at war, the Onna-bugeishawere a type of female warrior belonging to the Japanese nobility. These women managed to protect their homes for more than two thousand years mostly using a weapon known as anaginata. At this time, even the Onna-bugeisha were not allowed to travel alone, but only in the company of a husband, samurai, or another man and with written administrative permission. In the seventeen century, the role of Japanese women became that of mere dolls. Many samurai viewed women purely as child bearers and the concept of a woman being a fit companion for war was no longer present. This relationship between husband and wife was the same as that of a lord and his vassal. Samurai wives did not sleep in the same room with their husbands. At the whim of the samurai, he would go to his wife's room and she, like a slave, fulfilled all of his requests. Women did not go to school or do activities requiring heavy labor. All work was split into women's and men's work. This continues in many cultures around the globe, but in Japan, it was in its most divided and extreme form. If such a relationship existed between a Japanese man and his wife, it is easy to imagine how the invading Japanese samurais treated Okinawan women. The Japanese treated the Okinawans as a sort of lower race. Those who did not know the Japanese language wore special plates around their necks that labeled them as non-Japanese speakers in order to protect their lives. If a samurai asked such a person a question and they did not answer, the samurai accepted this as an insult and immediately cut that person's head off. The samurai in Okinawa did not have much of a salary, so they took the right to go around the farms and demand that the peasants offer them food, sake, and a place to stay. There was no penalty for raping peasant women at that time, so they had what would have been considered an enjoyable life. Among other things, this led to the fact that many members of the Okinawan population have Japanese genes (Omoto, Saitou 1997, pp. 102, 437-446).

At that time, men treated women badly in Europe, too. Around 1500, the English invented the scold's bridle: a medieval instrument that deterred women's chatter. A woman's duty was to stay at home, take care of the home, have children, and raise those children.

In response to the hard life created by their superiors, common people have always found ways of escaping or adopting their intruding obligations (Certeau 1990, pp. 40-42). Throughout history, it has been well known that the leading class, the one at the top of society, could not ever totally suppress a revolt of the common people against their enforced rules. The common people always found a way out, no matter if it was a matter of religion, the political system, or just paying taxes. Revolts always spread amongst common people like wildfire.

唐 Kara 手Te where Kara means China and Te the means hand emerged in Okinawa, the name later evolved to 空 Kara 手Te where Kara means empty and Te means hand. Same happened in the sixteenth century 
in Brazil where Capoeira emerged as Self-defense amongst black slaves. The slaves were completely without entitlements, unprotected and exposed to their owners' will. Therefore, they searched for protection. Out of this situation, Capoeira was born. They masked their practicing so that they did it in the form of a dance followed by the music of drums and other available instruments. This is very similar to Kata being practiced as dancing in the rice fields. In both cases, you cannot understand at first glance for what purpose or for whom this was created. There is a big difference between Capoeira and Kata. The slaves worked hard on the sugar fields, so they were strong and able to do jumps and many other gymnastic movements, but they did not have an education, so they based Capoeira on human power with the singular purpose of killing. In contrast, masters with knowledge of medicine, acupressure, and war strategies created Kata forms as an art of self-defense. Something very similar happened to the Angampora martial art in Sri Lanka. After the British occupied the whole island of Sri Lanka in 1815, they banned the practice of Angampora in 1817. They burned down all of the practice huts they found and shot anybody found practicing this art in the knee. Angampora had nearly disappeared by 1948, when Sri Lanka became independent. However, many forms survived masked in national dances. Besides the above martial arts, it is and has always been very common to use fighting moves in dances - just imagine North American Indians dancing around the fire or dances in Africa.

\section{For Whom As a Logical Aspect}

We can freely say that the Edo period, with the Japanese invasion, was a harsh time for the Okinawans, so they had to find a way to protect themselves. This led to the development of Kata, learned by dancing in the rice fields due to the ban on martial arts training that existed at the time. All forms of Kata self-defense had to be fast and effective. There was no excuse for disobedience. Samurais had only one punishment for Okinawans - death. On the Okinawans' side, this meant that in the case of disobedience they would have to kill the samurais before the samurais killed them. They needed to find a way to protect themselves from weapons with their empty hands (carrying weapons was forbidden at the time). This protection had to be so fast that nobody could see it. The protection had to allow a weaker person (a woman) to defend herself from a skilled warrior (a samurai). And, most importantly, the technique had to result in killing the samurai. They could not leave the samurai alive, as this would lead to a death sentence for them.

All the original Kata developed before the Meji period except the basic San Chin Kata have the complete action forms covered in six steps. It is believed that San Chin was spread by its creator, Bodhidharma. San Chin Kata is performed in the Jin stance, redirecting the attacker's energy and passing it by. San Chin Kata only has three defensive techniques, with none of the punches or strikes that other forms of Kata have:

1. Stepping in or entering, or otherwise coming closer to the attacker. The attacker alone mostly does this.

2. Positioning your body towards the attacker's safe place or at least turning his head away to move out of his sight. The same meaning can be found in master Sun, who says, "In ancient times, an experienced warrior first assured his own in vulnerability and then waited for the enemy's vulnerability" (Tzu 2009, pp. 80-276).

3. Punching or pressing pressure points to cause a "softening" of muscle strength or unconsciousness.

4. Breaking legs or hands to make the attacker incapable of fighting further.

5. Breaking the neck or using pressure point fighting methods to kill.

Besides the above rules, it is important to distinguish between sport and real life to understand Kata forms. In karate as a sport, we mostly see blocking and punching with boxing fists to protect competitors from injuries. Karate, as with any other sport, deals with Agon (ranking competitors by weight). Grabbing is mostly forbidden and hitting vital points and breaking bones is not allowed. Therefore, if you look at the old, original White Crane style Kata from a sporting perspective, it is impossible to understand them. Kata forms teach all possible techniques that would allow a weaker person to prevail over a stronger one. At first, there is no blocking because a weaker person cannot stop a stronger and heavier person. The techniques begin with grabbing and continue with catching as Tiger and Leopard would do. Everything is based on five animal styles. 
Kata uses lever techniques to enlarge a weaker person's force and break bones or injure joints. Oi Tsuki is used for catching and Gyaku Tsuki (with hips turning) is used to enlarge the punching energy. For the same reason, nearly all techniques are double handed: one pulling and one punching to double the defender's force. There is no boxer fist form! The boxing fist was introduced for sporting purposes because, as Funakoshi writes in his book, a blow from a fist rarely results in external wounds (Funakoshi 2013, p. 57)!

Kata forms use six Ji hands (McCarthy 2016, pp. 22). You may find the six Ji hand form drawings in Bubishi, but the drawings are done, as everything else, in order to be completely misleading. Namely, what you see and understand at first glance is not its true application. Ji is usually translated from Chinese as "strike," but this is, as everything written or drawn on Chinese martial arts, misleading. There is another translation for Ji: "concubine." Concubine is by pronunciation the same word with a different stress, but written differently. Therefore, the hidden name clearly tells us that even concubines can use these hand forms for self-defense.

Out of the six Ji hand forms, two are used for catching:

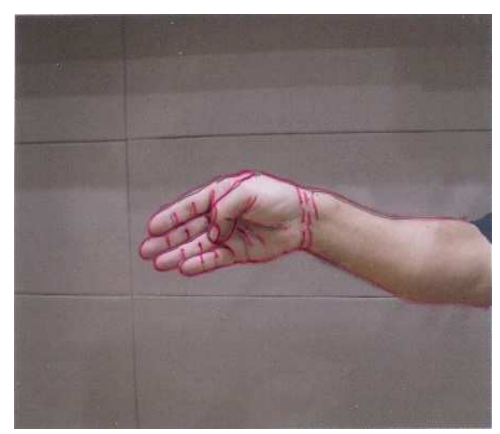

Image 1. Sword Hand Source: Sefer 2013, p. 42.

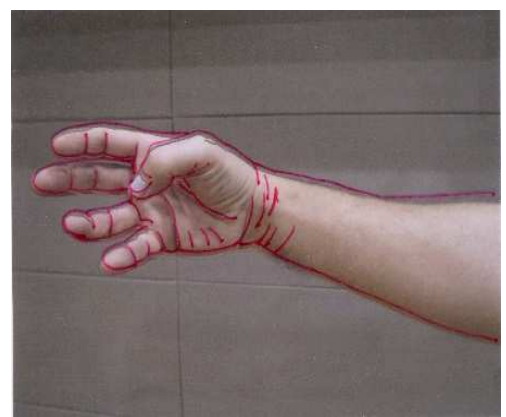

Image 2. Claw Hand Source: Sefer 2013, p.

Four other forms are for hitting on acupressure points:

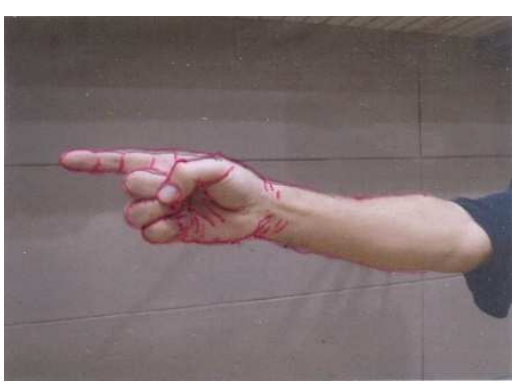

Image 3. One Blade of Grass Source: Sefer 2013, p. 24.

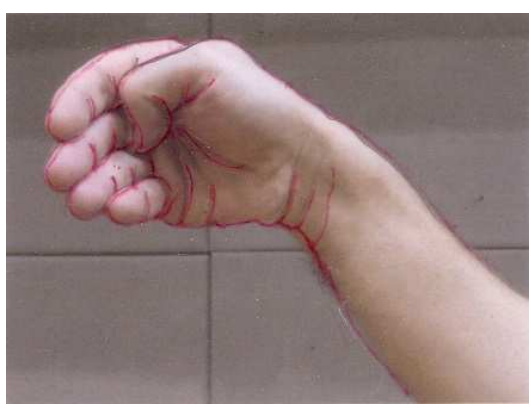

Image 5. Blood Pool Hand Source: Sefer 2013, p. 34.

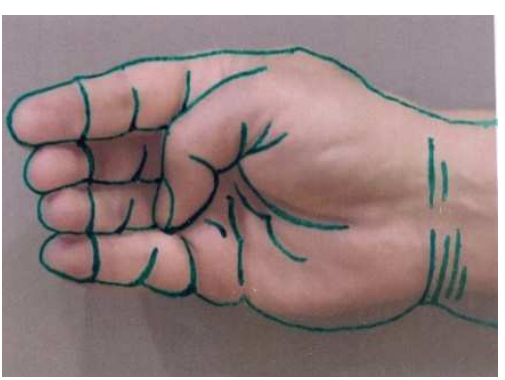

Image 4. Iron Bone Hand Source: Sefer 2013, p. 30.

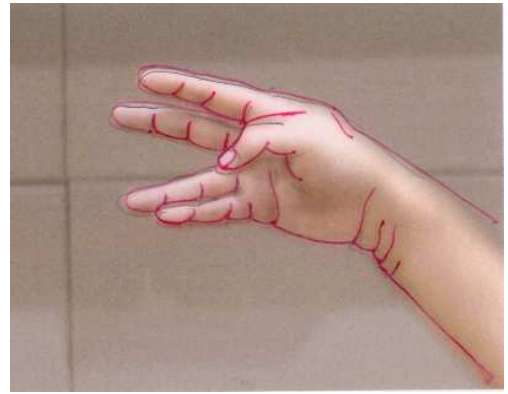

Image 6. Iron Sand Palm Source: Sefer 2013, p. 36. 
Besides Ji hand forms, there are also two other forms:

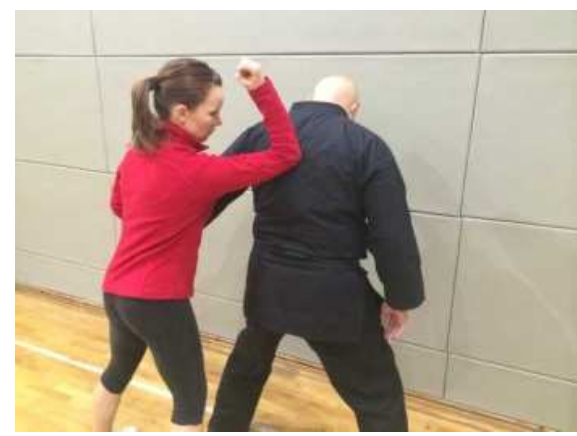

Image 7. Empi form for stabbing Source: own study.

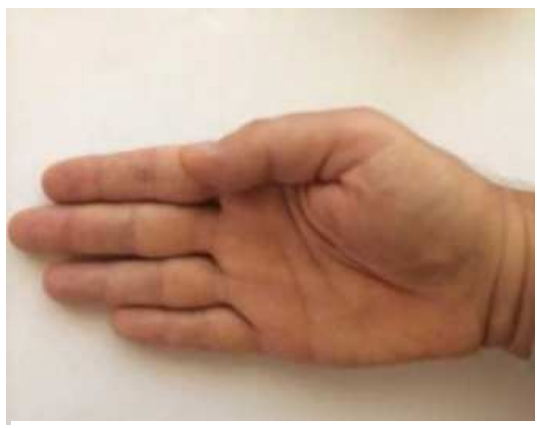

Image 8. Nukite form for neck breaking Source: own study.

In Nukite the fingers are in the Wood Stimulating position to intensify punches on the ST5 jaw pressure point to cause unconsciousness and to soften the neck and make it easier to break.

All of these actions have a basis in the philosophy of five animals. The essence of these techniques is to give the advantage to a weaker and smaller person (a woman). In addition, through many years of teaching I have discovered that some Kata form actions cannot even be executed in full efficiency by a stronger person on a weaker person due to the weaker person's lack of muscles and accordingly soft and flexible body. At the same time, these actions are very effective when executed by a weaker person on a stronger person with a muscular body that is "hard as a rock."

Before concluding, I must again express that it is commonly known and accepted that the Okinawan Kata forms originated from the White Crane style and the creator of the White Crane style was a woman. To conclude, I am describing the legend of Fāng Qīniáng, which indisputably confirms that Kata forms were made for women's self-defense against the male-styled "hard as a rock" attack.

The Fāng family lived in a place where there were many cranes. Fang's father knew the southern Chinese martial arts and taught them to his daughter. The legend says that Fang tried to banish a bird using a stick and the skills she learned from her father, but whatever she did, the crane would counter. Fang tried to hit the crane on the head, but the bird moved its head out of the way and blocked the stick with its wings.

Fang tried to hit the crane's wings, but the crane stepped to the side and this time blocked with the claws of its feet. Fang tried to poke the crane's body, but the crane dodged backwards and struck the stick with its beak. From then on, Fang carefully studied the movements of cranes and combined these movements with the martial arts she learned from her father, creating the White Crane style of the Fujian province. There are many versions of this legend. The most important to understanding Kata are those in which the crane does not block the stick Qīniáng used, but evaded and countered. Cranes do not block, they push aside! This is most important point to understanding Kata.

Even imagining how the white crane (bird) moves tells that this is a skill, elegance, and art of movement that has nothing in common with a muscular man. The point of the style is to make less use of physical strength, stressing evasion and attacks to vulnerable areas instead. White Crane fighting elements are popular, especially in women's self-defense, because they do not depend on strength, and women are better able to imitate the pecking motion so common in the crane style of fighting. The legend further speaks of how an invincible man, Zeng Cishu, who was a hard-style boxing expert with fingers like iron and a body as hard as rock insisted on doing battle with Qīniáng, then a sixteen-year-old girl. Qīniáng got through the fight without being hit once. Zeng Cishu went on to become Qīniáng's most prized student and eventually became a second-generation master of the White Crane style. This legend and evidence of Fāng Qīniáng's existence clearly proves that the White Crane style was created by a woman for women as an art of self-defense. This is also evidence that Kata forms are an art for which you do not need to be "hard as a rock." 
Besides the legend of Fāng Qīniáng, the fact that Giching Funakoshi (who was, even by Japanese standards, a small person) effectively used karate to protect himself proves that Kata is the art of self-defense for a weaker person against a stronger person.

\section{Conclusion:}

The following are answers to questions concerning Kata's purpose, including when, why, and for whom Kata were created:

The purpose of Kata forms is self-defense.

The creation of Kata forms started with Bodidharma, but the creation of Kata in Okinawa was expanded by the Chinese or Okinawans with Chinese roots after the beginning of the ban in 1477 that prevented the carrying of weapons and the training of martial arts.

The Okinawan people needed something to defend themselves against the Japanese after they invaded Okinawa in 1609.

The most important conclusion is that Kata is the art of self-defense and that you do not need fingers like iron or a body as hard as a rock to use Kata knowledge in real life situations.

Kata forms are for women's self-defense, meaning they are meant to defend a weaker person from a stronger person.

\section{REFERENCES}

I have bought many books and read even more, but I did not find another author who has done the same or similar research that I have. I have listed the authors whose explanations I am directly using in this article but there are many others who helped me to create the idea for this article.

Alexander, W.G, Penland, K. (2015). Bubishi Martial Art Spirit. Palm coast Florida: Yamazato Publications.

Barnhart Richard M, Xin, Y., Chongzheng, N., Calhill, J., Shaojun, L., \& Wu, H.. (1997). Three Thousands Years of Chinese Painting. New Haven: Yale University

Certeau, M. (1990). L' invention du quotidien [The invention of everyday life]. Paris: Editions Gillimard.

Clavell, J. (1975). Shogun. New York, NY: Delacorte Press.

Funakoshi, G. (2012). Karate-Do: My Way of Life. USA: Kodasha.

Funakoshi, G. (2012). The Twenty Guiding Principles of Karate. USA: Kodasha.

Funakoshi, G. (2013). The Essence of Karate. USA: Kodasha.

Huizinga, J., Caillois, R., \& Fink, E. (2003). Teorijaigre. Ljubljana: Študentska založba.

McCarthy, P. (2016). Bubishi: The Classic Manual of Combat. North Clarendon, VT U.S.A.: Tuttle Publishing.

Omoto, K. \& Saitou, N. (1997). Genetic origins of the Japanese: A partial support for the dual structure hypothesis.

American Journal of Physical Anthropology.

Sefer, E. (2013). In Kata Is Everything You Need. (3 ${ }^{\text {rd }}$ ed.). Dolenjske Toplice: Schäffer Consult.

Sefer, E. (2016) Private collection Dolenjske Toplice.

Sefer, E. (2016). Private collection Dolenjske Toplice.

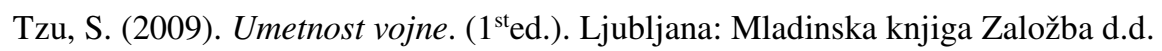

AUTHOR'S ADDRESS: $\quad$ Edvard Sefer

Meniska vas 86

SLO-8350 Dolenskje Toplice

Slovenia

E-mail: sefer@siol.net

Received: 26 June 2017; Accepted: 15 July 201 